\title{
Factors Influencing the Awareness and Adoption of Borehole-Garden Permaculture in Malawi: Lessons for the Promotion of Sustainable Practices
}

\author{
Rebekah G. K. Hinton 1,2,*D, Christopher J. A. Macleod ${ }^{2} \mathbb{D}$, Mads Troldborg ${ }^{2} \mathbb{D}$, Gift Wanangwa ${ }^{3,4}$, \\ Modesta Kanjaye $^{3}$ DD, Emma Mbalame ${ }^{5}$, Prince Mleta ${ }^{3}$, Kettie Harawa ${ }^{6}$ and Steve Kumwenda ${ }^{6,7}$ \\ and Robert M. Kalin ${ }^{1}(\mathbb{D}$
}

check for

updates

Citation: Hinton, R.G.K.; Macleod, C.J.A.; Troldborg, M.; Wanangwa, G.; Kanjaye, M.; Mbalame, E.; Mleta, P.; Harawa, K.; Kumwenda, S.; Kalin, R.M. Factors Influencing the Awareness and Adoption of Borehole-Garden Permaculture in

Malawi: Lessons for the Promotion of Sustainable Practices. Sustainability 2021, 13, 12196. https://doi.org/ $10.3390 /$ su132112196

Academic Editor: Alessio Siciliano

Received: 15 October 2021 Accepted: 1 November 2021 Published: 5 November 2021

Publisher's Note: MDPI stays neutral with regard to jurisdictional claims in published maps and institutional affiliations.

Copyright: (C) 2021 by the authors. Licensee MDPI, Basel, Switzerland. This article is an open access article distributed under the terms and conditions of the Creative Commons Attribution (CC BY) license (https:// creativecommons.org/licenses/by/ $4.0 /)$.
1 Department of Civil and Environmental Engineering, University of Strathclyde, Glasgow G1 1XJ, UK; robert.kalin@strath.ac.uk

2 The James Hutton Institute, Craigiebuckler, Aberdeen AB15 8QH, UK; kit.macleod@hutton.ac.uk (C.J.A.M.); mads.troldborg@hutton.ac.uk (M.T.)

3 Department of Water Resources, Ministry of Forestry and Natural Resources, Government of Malawi, Private Bag 390, Lilongwe, Malawi; gjwanangwa@gmail.com (G.W.); modesta.banda@gmail.com (M.K.); princemleta@gmail.com (P.M.)

4 Department of Earth Sciences, Environmental and Water Sciences, University of the Western Cape, Private Bag X17, Bellville 7535, South Africa

5 Department of Water Supply, Government of Malawi, Private Bag 390, Lilongwe, Malawi; emmambalame5@gmail.com

6 Water for People, Blantyre P.O. Box 1207, Malawi; kharawa@waterforpeople.org (K.H.); smkumwenda@yahoo.co.uk (S.K.)

7 BASEflow, Galaxy House, Blantyre P.O. Box 30467, Malawi

* Correspondence: rebekah.hinton@strath.ac.uk

\begin{abstract}
Using wastewater accumulating around rural waterpoints to irrigate community gardens, borehole-garden permaculture (BGP) presents a method of sustainable water management. BGP also presents public health benefits through the removal of stagnant water around boreholes, key Malaria breeding grounds, and through providing year-round food to supplement diets. By analysing a dataset of over 100,000 cases, this research examines the awareness and adoption of BGP across Malawi. Generalised linear models identified significant variables influencing BGP awareness and uptake revealing that socioeconomic, biophysical and waterpoint-specific variables influenced both the awareness and adoption of BGP. BGP had low uptake in Malawi with only $2.4 \%$ of communities surveyed practising BGP while $43.0 \%$ of communities were aware of BGP. Communities in areas with unreliable rainfall and high malaria susceptibility had low BGP awareness despite BGP being particularly beneficial to these communities. This work suggests that future work in the promotion of BGP should focus their efforts within these areas. Furthermore, this work highlights the value of community networks in knowledge sharing and suggests that such social capital could be further used by NGOs and the Government of Malawi in the promotion of BGP and other sustainable practices.
\end{abstract}

Keywords: permaculture; borehole management; sustainable practice; SDG6; Malawi; Africa; adoption; awareness; generalised linear model

\section{Introduction}

Malawi is a largely agro-based economy marked by subsistence, small-holder farming. Almost $80 \%$ of the population is reliant on rain-fed, small-holder agriculture [1]. Malawi is one of the poorest countries in the world with $50.7 \%$ of the population living below the poverty line and $25 \%$ living in extreme poverty [2]. Food insecurity is also prevalent; around $20 \%$ of the population are classed as undernourished [3]. The largely rain-fed nature of subsistence farming and limited resources of many farmers make Malawi's food supply particularly sensitive to water and climate stresses $[1,2,4]$. Climate change will worsen the 
fragility of agriculture in the region through an increased frequency and intensity of extreme weather events such as droughts and floods $[5,6]$. Pressure is further applied to natural resources and food security due to the growing population; Malawi is projected to have a five-fold population increase by 2100 [7]. Furthermore, plans for agricultural development in Malawi including the expansion of irrigation, will result in more water-stress in some regions [8]. Conservation and climate-smart agricultural technologies will be an important part of ensuring a sustainable future in Malawi's agricultural development [2,9-11], this has been acknowledged in country's own development plans [1]. To ensure maximal uptake of such practises, understanding how communities become aware of and adopt sustainable agricultural practises will be critical.

Over 100,000 water-points such as boreholes, hand-dug wells, and surface water provide the domestic water supply for around $65 \%$ of Malawi's population $(82.3 \%$ of the rural population and $19.8 \%$ of the urban population respectively) [12]. Most of these water-points consist of boreholes fitted with hand pumps designed to provide water for up to 250 people. Many boreholes were originally constructed by the Government of Malawi (GoM); however, since the 1990s, non-governmental organisations (NGOs) and the private sector have massively increased the number of boreholes. Boreholes provide improved water provision as they are not reliant on rainfall and river flow which can be unreliable; however, unsustainable water use is currently leading to the depletion and degradation of groundwater in Malawi [13-15]. Unsustainable water use in Malawi is anticipated to increase with population growth and an increasingly commercialised agricultural system implementing large-scale irrigation [12]. Encouraging patterns of sustainable water management and will be essential for Malawi in achieving sustainable development goal 6 (SDG6): clean water and sanitation [16]. Furthermore, ensuring sustainable agricultural practices that promote sustainable water management strategies will be key to ensuring Malawi will meet sustainable development goal 2 (SDG2): zero hunger [17].

Borehole-garden permaculture (BGP) presents one example of sustainable water management. Excess water around boreholes accumulates as a result of rainfall, water spilt during borehole use, and some users using the borehole as a washing point [18]. Many boreholes are fitted with concrete 'aprons' at the base of boreholes alongside a soakway used to channel runoff water away from the waterpoint [19]. BGP proposes a method of borehole management in which excess water accumulating around boreholes is channeled into community-managed gardens (typically at the end of the soakway), providing a low-cost and sustainable method of irrigation for community gardens [20,21]. Effective BGP gardens can provide year-round food to supplement diets and have therefore been proposed as a method of increasing food security. Training, resourcing, and promotion of BGP is provided by a variety of stakeholders including NGOs and the GoM $[20,22,23]$. Alongside the benefits of sustainable water use and increased food security and nutrition, BGP presents public health benefits through removal of stagnant water which act as key breeding grounds for the malaria transmitting Anopheles mosquitoes and other water-borne diseases such as bilharzia [24]. Rivett (2018) [20] also proposed that funds generated from BGP could supplement the costs of borehole maintenance in Malawi. Work to expand the scope of sustainable agricultural and water management techniques, such as BGP, in Malawi has been carried out for more than 30 years $[20,22,23]$. However, despite the many advantages of the practice, this study found that uptake of BGP around Malawi has remained low with only $2.4 \%$ of water-points across Malawi adopting BGP.

Malawi's agricultural development plan involves the formation of cooperatives by small-holder farmers; small-holder cooperatives would enable access to increased financing to adopt technologies [25]. As a largely community-led practice, understanding the uptake of BGP should elucidate some of the complex nature of community adoption of agricultural techniques [26-29]. Understanding decisions made by group co-option of sustainable agricultural practises may further illuminate how best to target messaging regarding climate-smart agriculture to newly formed small-holder cooperatives. The lessons learnt 
relating to how a community adopts BGP may become evermore important in the changing landscape of Malawi's agricultural sector.

This study aimed to enhance the understanding of BGP in Malawi through focusing on the research questions: (1) What is the extent of BGP awareness and adoption in Malawi? (2) Do the analysed variables influence BGP awareness and adoption? (3) What lessons for the future promotion of BGP can be learnt from where communities are aware of or adopt BGP? A dataset of over 100,000 water-points from across Malawi was analysed to identify the scope of BGP awareness and adoption. Evaluating socioeconomic, biophysical, and waterpoint specific factors through generalised linear model construction enabled this study to identify the key driving factors in BGP awareness and adoption.

\section{Materials and Methods}

\subsection{Research Context}

Malawi is a landlocked country in Sub-Saharan Africa, Figure 1. The current population of 19 million people is projected to increase by five-fold within the next 80 years [7]. As a largely agrarian state, agriculture contributes around $21 \%$ of the country's gross domestic product (GDP) [30] and 75\% of its exports [31]. Rain-fed agriculture is prominent, and most of the population (almost 80\%) are reliant on rain-fed small-holder agriculture [1]. However, such reliance on rain-fed agriculture makes Malawi's food supply vulnerable to climatic events; the combined effects of devastating floods in 2014-2015 and dry periods in 2015-2016 resulted in agricultural drought, this is estimated to have left over 6.7 million people food-insecure [32]. Furthermore, Malawi loses an average of $1.7 \%$ of its GDP each year to losses resulting from droughts and flooding [33]. Malawi's vision of becoming an inclusive and self-reliant nation [1] recognises the need for developing a more reliable and resilient food system, this includes proposing the expansion of irrigation to provide a reliable water supply. Malawi has seemingly rich water resources due to the presence of lake Malawi and a network of rivers. However, Malawi's water resources will be put under increasing pressure due to climate change, projected population growth, and the intensification of agriculture including the expansion of irrigation [5-8,34]. Changes in land use, such as deforestation, largely influenced by agricultural development, will further place pressure on water resources [1,34-37].

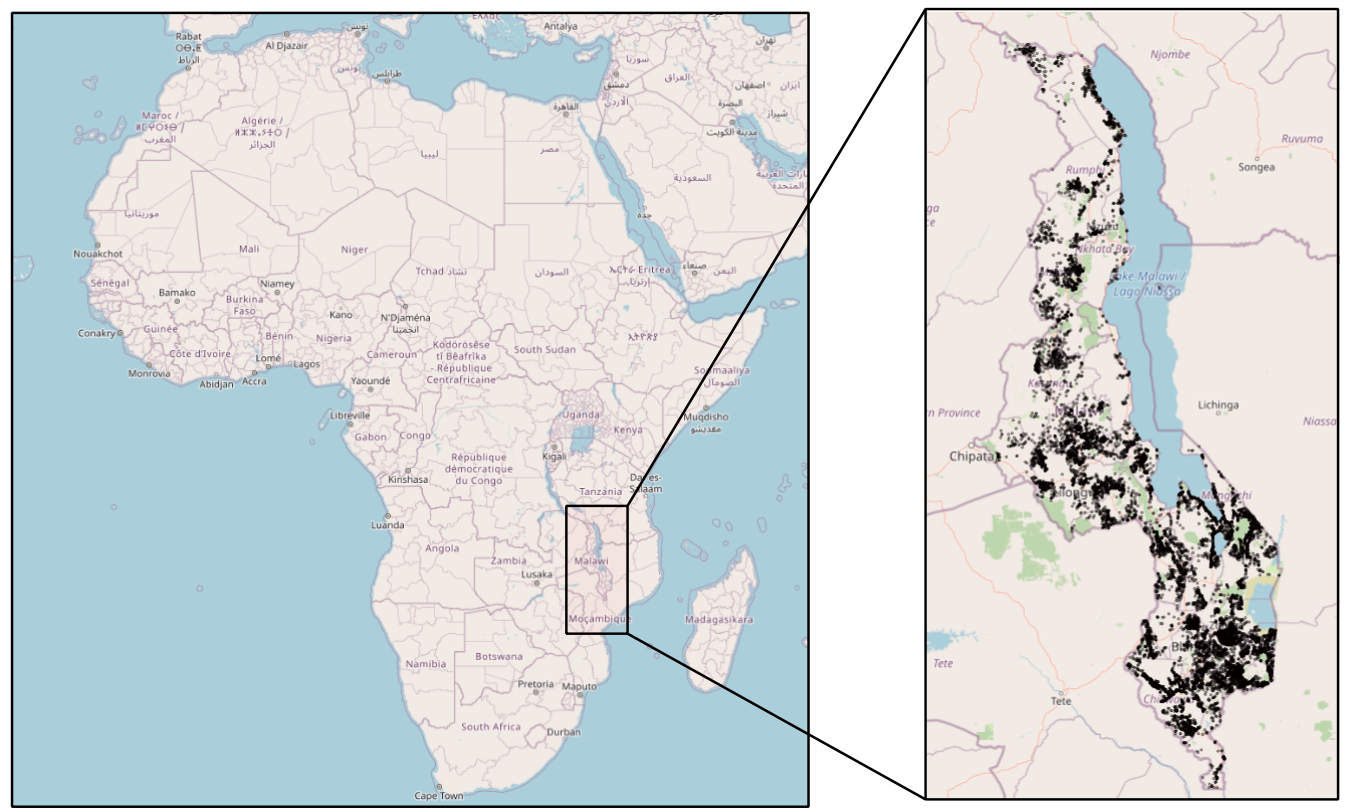

Figure 1. Map of Malawi with the point locations of water-points analysed in this study. 


\subsection{Waterpoint Survey}

Data from over 100,000 water-points across Malawi, regarding the status of each rural waterpoint, was collected by the GoM through the Climate Justice Fund (CJF) between 2012-2021 [13,14,38,39]. Rural water-points around Malawi were systematically visited by trained GoM staff members who conducted questionnaire-based site inspections of the waterpoint and surveyed community members involved its management. Surveys were conducted in either English or Chichewa and the surveyors received training in survey conduction prior to the data collection. Data were quality-controlled at the University of Strathclyde. The data are accessed via a Management Information System (MIS) on the platform mWater $[39,40]$. A mixed-methods approach, qualitative and quantitative, was adopted to analyse the data [41].

The Malawian waterpoint survey provided qualitative survey data regarding how communities heard of BGP and, if rejected, why they rejected the practise [13]. Communities that reported they were aware of BGP but were not practising the technique were asked why they were not practising the technique. This was collated to identify some of the major reasons for the rejection of BGP. We identified the perceived barriers to the adoption of the practise.

\subsection{Variable Selection}

To inform the selection of variables, an exploration of literature evaluating variables influencing adoption of sustainable agricultural practices was conducted. Both 'social' and 'natural' variables were considered [42]. Biophysical constraints on the adoption of a sustainable practice are important for adoption [43,44]; however, social networks and social capital are also important [26-29,42]. Tey et al. 2013 [45] produced literature review of variables influencing the adoption of sustainable agricultural practices in Sub-Saharan Africa, these were classified into 6 major categories: socioeconomic, agroecological, institutional, information, perceived attributes, and psychology. Information regarding the perceived attributes of BGP, the psychology, information available, and institutional ties of the adopters were unavailable and beyond the scope of this research. Therefore, this research focused on variables classified as socioeconomic and biophysical (or agroecological) variables. Biophysical variables were identified as variables relating to the physical location of the waterpoint including climatic factors, biological factors, and connectivity to resources such as markets or other communities. Furthermore, variables relating to the waterpoint itself and waterpoint management were analysed based on literature highlighting the significance of the waterpoint committee in BGP adoption [20]. We investigated the influence of neighbour adoption of sustainable agricultural techniques through calculating the distance from each waterpoint to the nearest BGP practising waterpoint. The variables selected for analysis are summarised in Table 1.

\subsection{Variable Extraction}

Initial cleaning of the dataset to remove incomplete or duplicate cases resulted in 75,013 boreholes for analysis. Variable data were collected from open-source data including datasets from the Regional Centre For Mapping Of Resources For Development (RCMRD) [46] and SERVIR-Eastern and Southern Africa [47]. Data on the locations of districts and traditional authorities in Malawi was accessed from The Human Data Exchange [48] and was provided by the Malawi National Statistical Office in 2018.

Data were accessed as a raster file and the variables at each individual waterpoint were extracted using a geographic data analysis and the modelling tool 'Raster' [49] using R Statistical Software (version 4.1.0) [50] in RStudio [51]. Further information regarding the sources for each variable, their definitions, and the values of the data is provided in the Appendix A. Variables relating to the status of the specific waterpoint and management of the waterpoint were gathered from the waterpoint survey [13]. The distance between each individual waterpoint to the closest BGP practising waterpoint was calculated using information about the point locations of each waterpoint using Pythagorean theorem. 
The closest BGP practising waterpoint was identified though iterative calculation of the distances and updating the closest distance if a closer waterpoint was identified.

Table 1. Variables investigated for their influence on the adoption of BGP. Variables are grouped into 3 categories (Socioeconomic, biophysical, and waterpoint specific features).

\begin{tabular}{|c|c|c|}
\hline Category & Subcategory & Variable \\
\hline \multirow{6}{*}{ Socioeconomic } & \multirow{2}{*}{ Education } & Mother education \\
\hline & & Literacy level \\
\hline & Population & Population density \\
\hline & Poverty & Average poverty level \\
\hline & Healthcare & Healthcare infrastructure \\
\hline & $\begin{array}{l}\text { Female-headed } \\
\text { household }\end{array}$ & $\begin{array}{l}\text { Female-headed } \\
\text { household index }\end{array}$ \\
\hline \multirow{9}{*}{ Biophysical } & \multirow{3}{*}{$\begin{array}{c}\text { Climate and } \\
\text { water availability }\end{array}$} & Temperature trend \\
\hline & & Precipitation trend \\
\hline & & Irrigation index \\
\hline & \multirow{2}{*}{ Extreme weather events } & Forest fires index \\
\hline & & Riverine flooding index \\
\hline & Soil & Soil organic carbon index \\
\hline & Malaria susceptibility & Malaria susceptibility index \\
\hline & \multirow{2}{*}{ Connectivity } & Market accessibility time \\
\hline & & $\begin{array}{c}\text { Distance to closest } \\
\text { BGP practising waterpoint }\end{array}$ \\
\hline \multirow{7}{*}{$\begin{array}{c}\text { Waterpoint } \\
\text { specific features }\end{array}$} & \multirow{2}{*}{$\begin{array}{l}\text { Waterpoint committee } \\
\text { (WPC) }\end{array}$} & Number of people WPC \\
\hline & & Number of women on WPC \\
\hline & \multirow[b]{2}{*}{ Waterpoint users } & Number of waterpoint users \\
\hline & & $\begin{array}{l}\text { Maximum distance of users } \\
\text { to the waterpoint }\end{array}$ \\
\hline & Waterpoint functionality & $\begin{array}{l}\text { Number of months water } \\
\text { is unavailable }\end{array}$ \\
\hline & \multirow{2}{*}{$\begin{array}{l}\text { Maintenance and } \\
\text { management }\end{array}$} & $\begin{array}{l}\text { Preventative maintenance } \\
\text { performed }\end{array}$ \\
\hline & & $\begin{array}{l}\text { Tariff or user fee for } \\
\text { the waterpoint }\end{array}$ \\
\hline
\end{tabular}

\subsection{Generalised Linear Model Construction}

The adoption of BGP was viewed as a two-stage process: awareness of BGP followed by the decision to adopt or reject the technique [44]. Variables influencing both stages were investigated through the construction of generalised linear models (GLMs) [52]. The use of a GLM enabled the relationship between the binary response variable and independent, continuous, and binary predictor variables to be analysed. The adoption (or knowledge) of BGP was modelled as a binary variable, 'yes' being the practise (or knowledge) of BGP and 'no' being where BGP was not practised (or heard of). The default variable is taken as ' $\mathrm{No}^{\prime}$. As both categorical and continuous variables were being used to model a binary response variable, a logistic regression model was used [53] The GLM function in base R [50], using RStudio [51,54] was applied to generate the models. 
Forward-variable selection was used to generate a model providing the simplest possible explanation of the variables by iteratively adding predictor variables. The Bayesian Information Criterion (BIC) value was calculated at each stage and the model with the lowest BIC value was selected, therefore selecting the model which could adequately explain the data with the fewest variables [55]. The method is less susceptible to collinearity than reverse variable selection models (although collinearity between variables was also calculated, Section 2.6), which was particularly important for the selection of variables here as many of the variables are interrelated.

The data were subsetted into a training and testing dataset [56] through the random allocation of $70 \%$ of the dataset being used to generate the model and testing the model with the remaining $30 \%$ of the data [57]. The training subset was used to generate a GLM, and the R 'Predict' function [58] was used to predict whether a given waterpoint would adopt (or be aware of) BGP based on variable values. The predicted outcome was compared to the testing subset of the dataset [59]. A confusion matrix was used to calculate the accuracy, sensitivity (true positive rate), and specificity (true negative rate) of the model. Models containing all variables (not generated through forward-variable selection) were generated for where communities were aware of or practising BGP to confirm that forward-variable selection did not result in the loss of predictive power (Appendix A Tables A5 and A6). Repeating the process of forward-variable selection with different randomly generated training datasets resulted in the same variable selection.

Due to the low percentage of BGP adoption, an imbalance classification problem was identified in the model where BGP was adopted in communities aware of BGP. The ROSE function [60] was used in RStudio to oversample the minority class in the training dataset. Oversampling was selected as a method of balancing the highly unbalanced dataset as it ensures that there is no information loss [61]. There were no changes made to the testing dataset.

\subsection{GLM Assumptions}

GLMs have several probabilistic assumptions: linearity, response distribution, independence, and multicolinearity. [59]. Assumptions were checked for both GLM models using the R functions $\mathrm{lm}$ [62] and the Variance Inflation Factor (VIF) [63]. All assumption plots are in the Appendix A.

Linearity between the transformed response variable and the predictor is a key assumption of GLM. The linearity assumption was checked using a residuals vs fitted values plot, this was to confirm that there was no significant trend in the residuals. The models met the assumption on response distribution through examining the approximate normality of the deviance residuals. A Q-Q plot was constructed to identify any deviance residuals that are significantly non-normal. The independence assumption was confirmed through the absence of autocorrelation in residuals. The lack of autocorrelation in residuals was identified through deviance residuals plots to confirm the absence of significant tracking of residuals. Finally, the assumption of a lack of multicolinearity was confirmed through the calculation of the VIF for each variable. The VIF value calculates the linear relations; a VIF value exceeding 5 suggests a problematic level of colinearity [64]. All VIF values calculated were below 3, confirming there was no problematic level of multicolinearity, Table A1.

\section{Results}

\subsection{Extent of Borehole-Garden Permaculture Uptake and Spatial Variation}

Overall, $43.0 \%$ of surveyed water-points in Malawi were aware of BGP $(32,256)$. Of those water-points, $5.6 \%$ (1800) had adopted the practise; an overall adoption of $2.4 \%$ across all surveyed water-points in the cleaned dataset $(75,013)$. A map of where BGP is practised highlights the spatial variation in BGP practise in Malawi with some regions showing a much greater percentage adoption than others, Figure 2. 

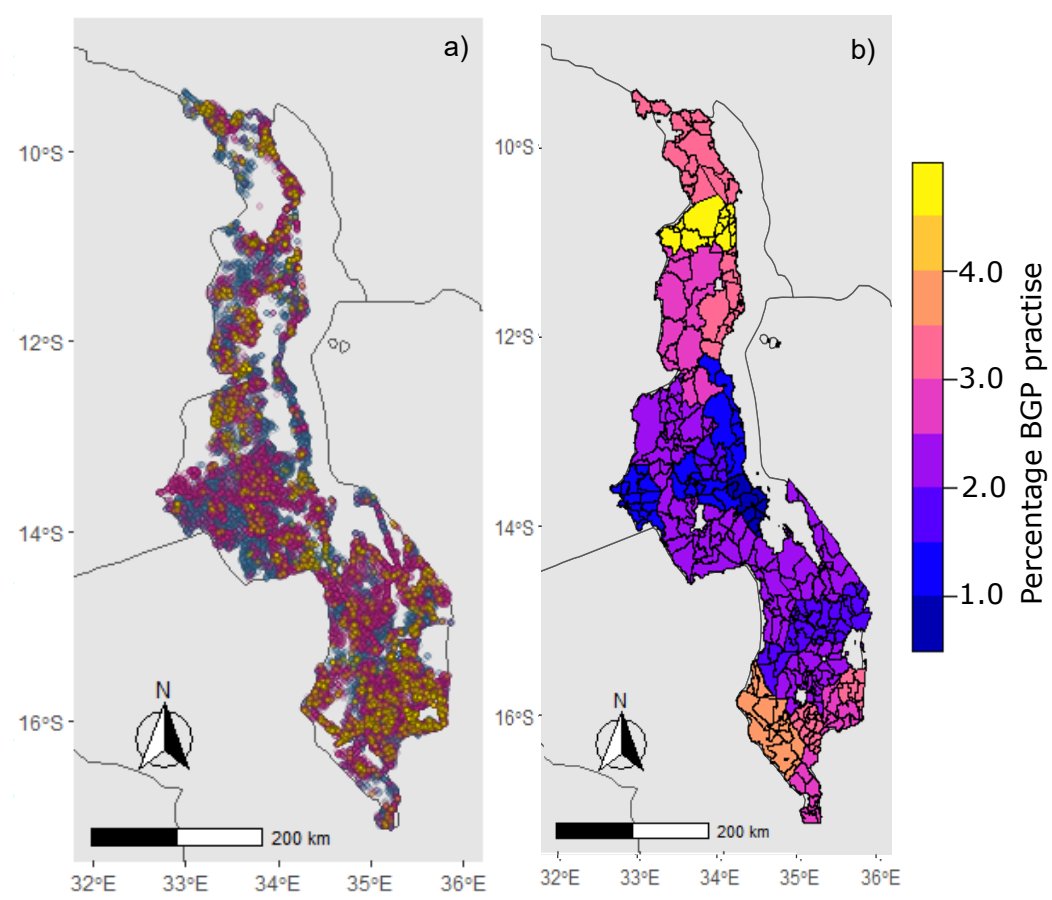

Figure 2. The distribution and percentage adoption of BGP in Malawi. (a) Depicts whether each waterpoint surveyed practised BGP (yellow), were aware of BGP but was not practising it (magenta) or had not heard of BGP (blue). (b) The percentage of water-points in a district which practise BGP. Traditional authority lines are shown too.

The district with the lowest BGP practise, Likoma, had $0.08 \%$ of water-points practising BGP, while the district with the highest percentage of BGP, Rumphi, had $4.5 \%$ of waterpoints practising BGP, Table 2. A summary of the individual adoption percentages of each district is provided in the Appendix A.

Table 2. Percentage of waterpoint in each district that adopted BGP.

\begin{tabular}{cc}
\hline District & Percentage of BGP Practise \\
\hline Rumphi & 4.53 \\
\hline Chikwawa & 3.72 \\
\hline Mwanza & 3.55 \\
\hline Chipita & 3.25 \\
\hline Karonga & 3.20 \\
\hline Nkhatabay & 3.17 \\
\hline Phalombe & 3.01 \\
\hline Thyolo & 3.01 \\
\hline Nsanje & 2.97 \\
\hline Mzimba & 2.95 \\
\hline Mulanje & 2.79 \\
\hline Blantyre & 2.44 \\
\hline Ntcheu & 2.42 \\
\hline Dedza & 2.39 \\
\hline Chiradzulu & 2.38 \\
\hline Kasungu & 2.21 \\
\hline & \\
\hline & \\
\hline & \\
\hline & \\
\hline & \\
\hline & \\
\hline & \\
\hline & \\
\hline & \\
\hline
\end{tabular}


Table 2. Cont.

\begin{tabular}{cc}
\hline District & Percentage of BGP Practise \\
\hline Lilongwe & 2.16 \\
\hline Zomba & 2.16 \\
\hline Mangochi & 2.06 \\
\hline Ntchisi & 1.86 \\
\hline Machinga & 1.66 \\
\hline Balaka & 1.63 \\
\hline Neno & 1.60 \\
\hline Lilongwe & 1.46 \\
\hline Dowa & 1.44 \\
\hline Nkhotakota & 1.38 \\
\hline Mchinji & 1.28 \\
\hline Salima & 0.09 \\
\hline Likoma & 0.08 \\
\hline
\end{tabular}

\subsection{Variables Influencing Knowledge of BGP}

Of BGP practising water-points that responded to the question 'How did you learn about permaculture?', 52.6\% reported having heard about BGP from neighbours, 25.3\% from the GoM, and $22.1 \%$ from an NGO, Figure 3. The locations of communities practising BGP and how they learnt about BGP were plotted to see if there were any significant differences in the spatial distribution of how communities had learnt of the practise. No noticeable clustering of how boreholes had come to learn about BGP was evident with the Malawian government, neighbours, and NGO capacity building about BGP widespread across Malawi.

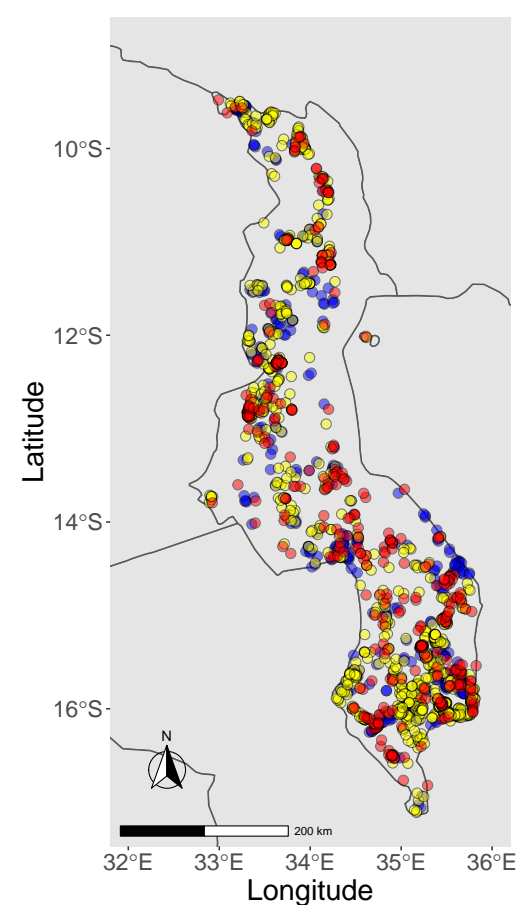

Figure 3. How communities practising BGP were aware of the technique represented spatially. Individual BGP practising water-points that were aware of BGP from the GoM are in red, neighbours are shown in yellow, and NGOs are shown in blue. 
The production of a forward-variable selection GLM enabled further investigation of variables contributing to where communities were aware of BGP, the results of the model are summarised in Table 3 . The GLM correctly predicted whether $71.9 \%$ of communities were aware of BGP.

Table 3. GLM produced using forward-variable selection to explain variables influencing where communities are aware of BGP. Variable estimates alongside standard deviation (shown in brackets) are given. BIC Value: 39,500 . AIC Value: 39,300 . The model correctly predicted $71.9 \%$ of cases where BGP has been heard of (9219 correct predictions, 3603 incorrect predictions). Sensitivity 0.516 , specificity 0.684$)$. Significance codes: ${ }^{* * *}(0<p \leq 0.001) ;{ }^{* *}(0.001<p \leq 0.01) ;{ }^{*}(0.01<p \leq 0.05)$. Non-significant results ( $p$-value $>0.05$ ) are marked with 'NS'.

\begin{tabular}{ccc}
\hline Variable & Variable Estimate $(\times \mathbf{0 . 0 0 1})$ & Significance \\
\hline Socioeconomic Variables & & \\
\hline Female-Headed Household & $+16.3 \pm 1.17$ & $* * *$ \\
Mother education level & $+4.21 \pm 0.423$ & $* * *$ \\
Population & $-14.0 \pm 4.90$ & $* *$ \\
Poverty & $+11.1 \pm 1.59$ & $* * *$ \\
\hline Biophysical Variables & & \\
\hline Irrigation & $+9.59 \pm 2.01$ & $* * *$ \\
Malaria susceptibility & $-11.9 \pm 0.864$ & $* * *$ \\
Market accessibility time & $+2.1 \pm 0.665$ & $* * *$ \\
Precipitation trend & $+6.94 \pm 0.908$ & $* * *$ \\
Riverine flooding & $-12.4 \pm 3.49$ & $* * *$ \\
Soil Organic Carbon & $-27.9 \pm 3.24$ & $* * *$ \\
\hline Distance to a BGP practising water-point & $-166 \pm 10.6$ & NS \\
\hline Water-point (WP) specific Variables & & $* * *$ \\
\hline How many people usually use this WP & $+0.0706 \pm 0.0235$ & $* * *$ \\
How many women are on the WPC? & $-8.97 \pm 7.42$ & $* * *$ \\
Maximum distance a user walks to WP & $+0.112 \pm 0.0264$ & \\
Preventative maintenance performed & $-133 \pm 29.8$ & \\
Tariff or user fee for the WP & $+142 \pm 35.8$ & \\
\hline
\end{tabular}

\subsection{Variables Influencing Adoption of Borehole-Garden Permaculture}

The forward-variable selection GLM of where BGP was adopted in communities that were aware of BGP using a balanced dataset correctly predicted $61.4 \%$ of where BGP was adopted. The results of the GLM model are summarised in Table 4.

\subsection{Reasons for Rejection of Borehole-Garden Permaculture}

The reasons given for why communities that were aware of BGP did not adopt the practise are summarised in Table 5. The most common reason was a lack of common land at the end of the soakway, this included both no land and owners of the land disallowing BGP.

The fourth most commonly listed reason for why BGP was not practised was due to non-functionality of the waterpoint or limited water. The functionality of surveyed waterpoints is shown in Table 6. Functionality is a temporally sensitive variable and represents only a 'snap-shot' of functionality at a given point in time [38,65], the classification of 'partially functional' alongside 'functional' and 'nonfunctional' water-points enables a clearer depiction of waterpoint functionality over time. 
Table 4. GLM using forward-variable selection to explain variables influencing where BGP is practised in places where it has been heard of. BIC value: 1920 AIC value: 1840. Correctly predicted the status of which boreholes adopted BGP in $61.4 \%$ of cases (3440 correct and 2165 false predictions). Sensitivity 0.551 , specificity 0.617 . A sample dataset an equal number of water-points that adopted and rejected BGP was analysed, a ratio of 70:30 was used for the data used for training:testing. Significance codes: ${ }^{* * *}(0<p \leq 0.001) ;{ }^{* *}(0.001<p \leq 0.01) ;{ }^{*}(0.01<p \leq 0.05)$.

\begin{tabular}{ccc}
\hline Variable & Variable Estimate $(\times \mathbf{0 . 0 0 1})$ & Significance \\
\hline Socioeconomic Variables & & \\
\hline Healthcare infrastructure & $+4.08 \pm 1.14$ & $* * *$ \\
Mother education level & $+3.80 \pm 4.63$ & $* * *$ \\
Female-headed household & $-8.01 \pm 1.08$ & $* * *$ \\
Poverty & $+9.11 \pm 2.22$ & \\
\hline Biophysical Variables & & $* * *$ \\
Precipitation trend & $+21.1 \pm 0.984$ & $* * *$ \\
Soil organic carbon & $+45.2 \pm 4.00$ & $* * *$ \\
Riverine flood index & $-76.2 \pm 12.9$ & $* * *$ \\
Market accessibility time & $+3.80 \pm 0.716$ & $* * *$ \\
Temperature trend & $+8.57 \pm 1.86$ & \\
Irrigation & $+11.8 \pm 2.51$ & $* * *$ \\
\hline Waterpoint (WP) specific Variables & & $* * *$ \\
\hline Number of months water is not available & $-120 \pm 1.10$ & $* * *$ \\
Number of women on the WPC & $+104 \pm 7.84$ & \\
Maximum distance a user walks to the WP & $+0.336 \pm 0.0274$ &
\end{tabular}

Table 5. The most common reasons given by communities that were aware of BGP but were not practising the technique for why they were not practising BGP.

\begin{tabular}{ccc}
\hline Reason for BGP Rejection & Incidence & Percentage \\
\hline No common land at end of soakway/not allowed & 13,000 & 42.2 \\
\hline Not interested & 7070 & 23.0 \\
\hline Lack of knowledge/awareness/no community training & 4310 & 14.0 \\
\hline Limited water/nonfunctional waterpoint & 2380 & 7.74 \\
\hline Limited money & 981 & 3.19 \\
\hline No access to seeds & 712 & 2.31 \\
\hline Yet to start/temporary pause & 649 & 2.11 \\
\hline Animals (eat crops or drink surplus water) & 497 & 1.61 \\
\hline Salty water/poor water quality & 457 & 1.48 \\
\hline
\end{tabular}

Table 6. Functional status given of water-points surveyed. Functional: a waterpoint that provides year-round water. Partially functional: a waterpoint that provides water but is not reliable. Nonfunctional/No longer exists or abandoned: water-points do not provide any water.

\begin{tabular}{ccc}
\hline Waterpoint Functionality & Incidence & Percentage \\
\hline Functional & 45,300 & 61.3 \\
\hline Partially functional but in need of repair & 15100 & 20.4 \\
\hline Not functional & 8410 & 11.4 \\
\hline No longer exists or abandoned & 5100 & 6.9 \\
\hline
\end{tabular}




\section{Discussion}

The variables influencing the awareness and adoption of sustainable agricultural techniques are complex $[10,11,45,66-71]$. BGP implementation requires decisions through community management and engagement. The adoption of BGP, and other sustainable agricultural techniques, is dependent on communities being aware of BGP and choosing to adopt the practise [10,44]. Both stages are influenced by a range of factors including socioeconomic, biophysical, and waterpoint specific variables [20,42,43]. Investigating the processes of communities becoming aware of BGP and adoption of the practise as individual steps, with unique variables influencing them, can help to elucidate areas of focus for policy and practise.

\subsection{Limitations}

Although this research analysed a range of variables including socioeconomic, biophysical, and waterpoint specific variables, this study did not analyse all the variables which influence this process, and it does not aim to provide a conclusive description of all variables involved. The socioeconomic variables analysed were a measure of the average level of the specific socioeconomic variable at a given location. Although this aimed to provide information on the average status of the community (i.e., poverty level), this may not be a true reflection of the status of the community as a whole. In the case of poverty, the average poverty level in a region may not sufficiently explain the availability of financing to a given community. This study revealed the large spatial heterogeneity of BGP adoption, while this may reflect the socioeconomic, biophysical, and waterpoint specific variables explored in this study, there are also significant regional differences. Many of these differences centre around traditional authorities and may reflect the differences culture and ethnography between regions. Although this study does explore some of the reasons why communities did not adopt BGP, further qualitative data would be beneficial to further explore the reasons behind BGP adoption and rejection.

\subsection{Summary of Variables Influencing BGP Awareness}

The knowledge of BGP is influenced by a range of variables including socioeconomic and biophysical variables as well as waterpoint specific considerations [10,42]. Population density was found to be an important variable, communities in areas with lower population densities (rural areas) were more likely to be aware of BGP, Table 7. The rural nature of BGP practise may also explain some of the other variables found to be significant in where communities were aware of BGP including poverty levels and the proportion of femaleheaded households, both of which are higher in rural areas [72]. However, such trends may not be completely explained by differences in rural and urban areas. For example, NGOs may also focus work in poorer areas too therefore leading to a higher level of BGP knowledge in poorer areas.

Biophysical geographical variables were significantly linked to where communities were aware of BGP, Table 7. Increased water availability, both through irrigation and precipitation, resulted in an increased knowledge of BGP. Areas with higher levels of irrigation generally have a more established agricultural sector, it may be that they are more likely to have heard of sustainable agricultural practises such as BGP. Although in the case of irrigation this may be partially explained by population density, no significant relationship between precipitation and population was observed indicating that the link between precipitation and BGP awareness cannot be explained by population density. 
Table 7. Summary of the results of analysed variables on BGP knowledge and adoption in a the minimal-variable GLMs in which variables were selected by positive variable selection. (+) denotes a significant positive variable estimate, $(-)$ denotes a significant negative variable estimate and 'NS' (not significant) is written for any variable estimate with a $p$-value of $>0.05$.

\begin{tabular}{|c|c|c|}
\hline Variable & BGP Awareness & BGP Adoption \\
\hline \multicolumn{3}{|l|}{ Socioeconomic Variables } \\
\hline Female-headed household & + & - \\
\hline Healthcare infrastructure & & + \\
\hline Mother education level & + & + \\
\hline Population density & - & \\
\hline Poverty & + & + \\
\hline \multicolumn{3}{|l|}{ Biophysical Variables } \\
\hline Irrigation & + & + \\
\hline Malaria susceptibility & - & \\
\hline Precipitation trend & + & + \\
\hline Riverine flooding & - & - \\
\hline Soil organic carbon & - & + \\
\hline Market accessibility time & + & + \\
\hline Distance to BGP practising waterpoint & - & \\
\hline Temperature trend & & + \\
\hline \multicolumn{3}{|l|}{ Waterpoint (WP) specific variables } \\
\hline Maximum distance a user walks to the WP & + & + \\
\hline Number of months water is unavailable & & - \\
\hline Number of users of the WP & + & \\
\hline Number of women on the WPC & NS & + \\
\hline Preventative maintenance performed & - & \\
\hline Tariff or user fee for the WP & + & \\
\hline
\end{tabular}

However, although areas with unreliable rainfall were less likely to be aware of BGP, these are some of the areas where BGP could be most beneficial through providing reliable irrigation to the BGP garden and enabling year-round food production [20]. Sustainable water management will become more critical with projected increases in temperature and reductions in rainfall in Malawi due to climate change, particularly in areas already experiencing water scarcity $[5,6]$. Areas already experiencing unreliable precipitation should be key targets of sustainable water management techniques such as BGP. As well as areas with lower precipitation trends, areas with high malaria susceptibility would benefit from BGP as the removal of stagnant water around boreholes prevents mosquitoes breeding [24]. However, despite the evident benefits, areas with an increased malaria susceptibility were less likely to be aware of BGP. Furthermore, this trend cannot be explained by communities in rural areas being more aware of BGP as Malaria susceptibility is negatively correlated with population density. This trend also does not appear to be the result of BGP practises already implemented in the area as adoption rates of BGP are not high enough to significantly change the malaria susceptibility. The underlying reason for why areas with less reliable rainfall and higher malaria susceptibility were less to be aware of BGP is not entirely clear. It is likely that these reflect where NGOs and influential individuals have focused efforts in expanding the knowledge of BGP [23].

Communities in which users walked further to access the waterpoint reported higher awareness of BGP, this may be explained in that rural areas have more disparate users and therefore this reflects the higher awareness of BGP in rural areas. Water-points with more users also had higher BGP awareness, despite rural areas having fewer users; the importance of the number of users of a waterpoint in where communities had heard of BGP highlights the importance of community knowledge [26-29,73,74]. The importance of 
community knowledge and social capital in where communities were aware of BGP was further highlighted by the significant role that neighbours played in increasing knowledge of the practice; communities closer to other communities practising BGP were significantly more likely to have heard of the practice. Furthermore, awareness of BGP from neighbours was the most commonly cited reason for how communities became aware of the practice, Figure 3.

External inputs also had a significant effect on which communities were aware of BGP. Communities that pay a tariff or user fee for the waterpoint had higher levels of BGP awareness. This may indicate that communities with active management have more external input and are more likely to be aware of BGP. However, the opposite trend was observed for communities with water-points for which preventative maintenance is performed; where preventative maintenance was performed there was reduced awareness of BGP. This was a surprising result and understanding the dynamics for why this may be the case was beyond the scope of this study; however, it does suggest that providers of preventative borehole maintenance could be used more in promoting awareness of BGP in communities.

\subsection{Summary of Variables Influencing Where BGP Is Adopted}

Regarding where borehole-permaculture is most likely to be adopted if communities are aware of the practice, physical constraints are important $[43,67]$. Communities in areas with reliable rainfall (higher precipitation trend) were more likely to adopt the practice. Communities in areas with increased levels of irrigation were also more likely to adopt BGP, suggesting a similar trend to precipitation in that communities in areas with greater water availability are more likely to adopt BGP. It may be that areas with more reliable rainfall and increased irrigation have a more robust agricultural system and therefore may be more inclined to adopt new agricultural techniques. Alternatively, areas with lower water availability may have alternative water priorities. For example, 'animals' was given as a reason for the rejection of BGP in areas aware of it in almost 500 cases: this referred to either animals eating crops grown or excess water being used as drinking water for animals. When limited water is available, retaining pools of water around boreholes to use as drinking water for livestock may be a higher priority for communities than using the water for crops [20]. Rivett et al., 2018 [20] suggested that water quality/salinity could be a constraint on BGP adoption as water salinity can prevent crop growth. Drier areas may have greater problems with salinity and therefore this may explain the reduced BGP adoption in areas with reduced precipitation trend [75]. The observed result that 457 water-points listed salinity or poor water quality as a reason for BGP rejection supports this. Although communities in areas with increased water availability showed greater adoption of BGP, communities at risk of riverine flooding were less likely to adopt BGP. This may become an evermore important consideration in encouraging the adoption of sustainable agricultural practices as climate change is likely to lead to an increased frequency of extreme weather events $[5,6]$. In the case of BGP adoption, the formation of a BGP garden requires investment of both time and finances. Communities at risk of riverine flooding may be less willing to invest the temporal and financial commitment required to develop a BGP garden if the garden is at risk of destruction by extreme weather events such as flooding. The temperature trend is another climatic variable that was significant in where BGP was adopted. Communities that were aware of BGP in areas with higher temperature trends were more likely to adopt BGP, the underlying reason for this trend is not understood. Soil fertility was another important consideration in BGP adoption, communities in areas with higher soil organic carbon were more likely to adopt BGP. It may be that areas with high soil organic carbon have a more robust agricultural sector and are more willing to adopt agricultural practises. Communities that had reduced access to markets were also more likely to adopt BGP. It may be that communities with reduced market accessibility have a greater requirement to grow their own food and therefore BGP gardens have a more significant role in supplementing diets. 
Other physical constraints, such as the absence of common land at the end of the soakway, were highlighted from asking communities why they were not practising BGP, Table 5. This was often due to land around boreholes being owned by individuals rather than by the water-users association of waterpoint committee. Such physical constraints in land availability may partially explain some of the increased prevalence of BGP in more rural communities. Waterpoint functionality is also a significant physical constraint; communities with water-points where water is unavailable for some months of the year were less likely to adopt BGP. Furthermore, partial or non-functionality was the 4th most commonly listed reason for why BGP was not taken up by communities aware of BGP. $35.2 \%$ of the surveyed water-points reported some level of non-functionality, ensuring improved waterpoint functionality in Malawi will therefore also be important in expanding the adoption of BGP.

The presence of an established waterpoint committee was an important variable in where BGP was adopted, emphasising the importance of community organisations and coordination in natural resource management [76]. The number of women on the waterpoint committee was a significant variable in where BGP was adopted; waterpoint committees with more women were more likely to adopt the practice. Waterpoint committee guidance stipulates that at least $50 \%$ of the waterpoint committee members should be women. Committees following the waterpoint committee guidance regarding female representation may be more likely to adopt other good practices in waterpoint management such as BGP. The maximum distance a user walks to collect water from a waterpoint was a statistically significant variable too, communities with more dispersed users appeared more likely to adopt BGP. It is not clear why this would be the case; however, the distance users walk is strongly correlated with both population density and the number of people who use the waterpoint.

Socioeconomic factors were also significant in where BGP was adopted in communities that were aware of BGP. The development of a BGP garden requires financial investment, limited money and no access to seeds were both cited as reasons for why communities that had heard of BGP did not adopt the practice, Table 5. Therefore, it was surprising that communities in areas with higher poverty levels were more likely to adopt BGP. It may be that communities in areas with high poverty levels are more reliant on initiatives such as BGP gardens to supplement diets and provide an additional source of income. Areas with higher levels of mother education had higher levels of BGP adoption highlighting the important role of women in BGP adoption. Female-headed household index was also an important variable in where BGP was adopted, communities in areas with higher proportions of female-headed households were less likely to adopt BGP. This may reflect the largely male-dominated nature of land holding and ownership in Malawi [77] in which the capacity for women to adopt BGP is restricted by land ownership, this would be an insightful area for further study. Healthcare infrastructure was another significant variable in where BGP was adopted, areas with more healthcare infrastructure had higher levels of BGP adoption. It is not entirely clear why this would be the case, however, as BGP has important public health benefits it may be that communities in areas with increased healthcare infrastructure will receive more encouragement to adopt practises which lead to the removal of stagnant water, such as BGP.

\subsection{Key Lessons for Government and NGOs}

BGP presents an effective technique for ensuring sustainable water use and is particularly beneficial as a method of sustainable irrigation in areas with unreliable rainfall. The removal of stagnant water from boreholes furthermore presents an important public health benefit through the removal of mosquito breeding grounds [24]. However, despite the evident benefits to communities, this investigation found communities in areas with a lower precipitation trend (unreliable rainfall) and with higher malaria susceptibility were less aware of BGP; the areas that stand to benefit most from the technique are less likely to 
have heard of BGP. This research therefore suggests that NGOs and the GoM should focus their work on expanding the awareness of BGP to such areas over the coming years.

Community management of boreholes has the capacity to provide a sustainable and empowering method of waterpoint management; reducing the reliance on external NGOs and government input [78]. However, concerns have been raised regarding community's capacity to reliably manage water-points $[13,79,80]$. Indeed, this study found that $35.2 \%$ $(28,560)$ of water-points surveyed reported being partial or non-functionality. Using proceeds from BGP to maintain boreholes provides an innovative solution to many of the challenges communities face in the management of boreholes [20]. Collaboration between stakeholders in sustainable agriculture and water management in Malawi is well established [9], this research highlights that collaboration between stakeholders in waterpoint management and those involved in BGP is also necessary in maximising the benefits and extent of BGP practise. Currently, areas with preventative maintenance performed on the water-points are significantly less likely to have heard of BGP, despite these water-points with greater external input. Engaging service providers responsible for borehole maintenance in spreading awareness of BGP and how to access training provides one method of ensuring increasing synergy between borehole management practises.

It is well established that social ties represent a critical consideration in the adoption of sustainable practises [26-29]. Throughout the process of the promotion of BGP, the value of neighbours and community ties cannot be underestimated. The proximity to neighbours practising BGP was not found to be a significant variable in where BGP was adopted in communities aware of it; this is despite this having been shown to be a significant variable in the adoption of other sustainable agricultural techniques $[28,29]$. This may partially be a reflection that social ties are more complex than merely a product of proximity [73]. However, proximity to a borehole-practising waterpoint was a significant variable in which communities were aware of BGP, highlighting the importance of social networks in the sharing of information $[73,74]$. Furthermore, neighbours represented the main way in which surveyed water-points reported being aware of BGP. NGOs and governments could capitalise on this resource by equipping communities to educate neighbouring communities about sustainable practices. Similar examples of practices have been seen in the promotion of sustainable agricultural practises elsewhere; for example, the Ethiopian government implemented an agricultural extension model bringing together a 'role model farmer' with four neighbouring farmers to promote social learning [29].

\section{Conclusions}

Combining qualitative and quantitative data collected in an extensive survey of over 100,000 water-points across Malawi [13,14,38,39], this research developed understanding of the status of BGP adoption in Malawi. Building on literature reporting the adoption of sustainable agricultural practises [20,26-29,42,43,45,71], this study identified some of the variables influencing where BGP is adopted and whether communities were aware of BGP by investigating socioeconomic, biophysical and waterpoint specific variables [44].

\subsection{A New Focal Area for BGP Promotion}

$43.0 \%$ of communities surveyed had an awareness of BGP. However, despite inputs from the GoM and many NGOs, BGP was practised at just $2.4 \%$ of the water-points investigated. The knowledge and uptake of BGP were dependent on a range of socioeconomic, biophysical, and waterpoint specific factors. This study highlighted areas where communities could benefit most from BGP, due to unreliable rainfall and high malaria susceptibility, were less likely to be aware of BGP. This research provides key policy recommendations suggesting that NGOs and the GoM should focus their work on expanding the awareness of BGP to these communities over the coming years. 


\subsection{Context Is Key}

Although the encouragement of sustainable techniques such as BGP are highly beneficial, they cannot be considered in isolation. The encouragement of BGP should be considered alongside other principles in waterpoint management such as the development of an established waterpoint committee and ensuring maintenance and proper functioning of water-points [78]; waterpoint functionality and waterpoint committee structure were key variables in the adoption of BGP. BGP adoption must also be considered in the context of the specific community and waterpoint, accounting for limitations in the context such as land ownership challenges or conflicting priorities for land and water usage such as livestock. However, the context of communities may also present an invaluable asset through pre-established social capital. Capitalising upon social contacts both between neighbouring communities and external service providers could provide an efficient mechanism of expanding the awareness of BGP in Malawi [26-29].

\subsection{Future Directions}

Ensuring the most effective method for the promotion of BGP will not only be critical in ensuring the maximal benefit of this technique but also provides key lessons in understanding the adoption of other sustainable techniques in Malawi. With pressure on Malawi's water resources projected to increase due to climate change [5,6], population growth [7] and agricultural intensification [1] understanding sustainable practises will be critical in achieving SDG2 [17] and SDG6 [16] (zero hunger and access to clean water and sanitation respectively). Furthermore, the proposals for the expansion of small-holder farmer cooperatives in Malawi's agricultural development [25] emphasise the need for understanding community decision making in sustainable land and water management. Investigating factors influencing the awareness and adoption of BGP in Malawi provides one example of community management of land and water. Exploring community awareness and adoption of other sustainable techniques in Malawi's land and water management will further guide policy makers and stakeholders in the promotion of sustainable practices.

Author Contributions: Conceptualization, R.G.K.H., C.J.A.M., M.T., R.M.K.; methodology, R.G.K.H., C.J.A.M., M.T., R.M.K.; software, R.G.K.H.; formal analysis, R.G.K.H.; investigation, R.G.K.H., C.J.A.M., M.T., G.W., M.K., E.M., P.M., K.H., S.K., R.M.K.; resources, C.J.A.M., M.T., R.M.K.; data curation, G.W., M.K., E.M., P.M., K.H., S.K., R.M.K.; writing—original draft preparation, R.G.K.H.; writing-review and editing, R.G.K.H., C.J.A.M., M.T., R.M.K.; visualization, R.G.K.H.; supervision, C.J.A.M., M.T., R.M.K.; funding acquisition, C.J.A.M., M.T., R.M.K. All authors have read and agreed to the published version of the manuscript.

Funding: This research was funded by the Scottish Government under the Scottish Government Climate Justice Fund Water Futures Programme research grant HN-CJF-03 awarded to the University of Strathclyde (R.M. Kalin). Funding was also received from the Scottish Government for the joint PhD studentship of R.G.K Hinton between the James Hutton Institute and the University of Strathclyde.

Institutional Review Board Statement: The study was approved by the Ethics Committee of the Government of Malawi.

Informed Consent Statement: Informed consent was obtained from all subjects involved in the study. All data collected was in line with the Government of Malawi ethics and was agreed with each interviewee.

Data Availability Statement: Confidential data was obtained from the Government of Malawi. Additional data was obtained from the publicly accessible repository RCMRD and is described within the Appendix A.

Acknowledgments: The authors wish to thank Stacia Nordin, Eston Mgala, and Nick Schurch for their helpful discussions and insights.

Conflicts of Interest: The authors declare no conflict of interest. 


\section{Abbreviations}

The following abbreviations are used in this manuscript:

MDPI Multidisciplinary Digital Publishing Institute

DOAJ Directory of open access journals

GoM Government of Malawi

BGP Borehole-garden permaculture

CJF Climate Justice Fund

MIS Management Information System

GLM General linear model

RCMRD Regional Centre For Mapping Of Resources139For Development

BIC Bayesian information criterion

VIF Variance inflation factor

NGO Non-government organisation

SDG Sustainable development goal

\section{Appendix A}

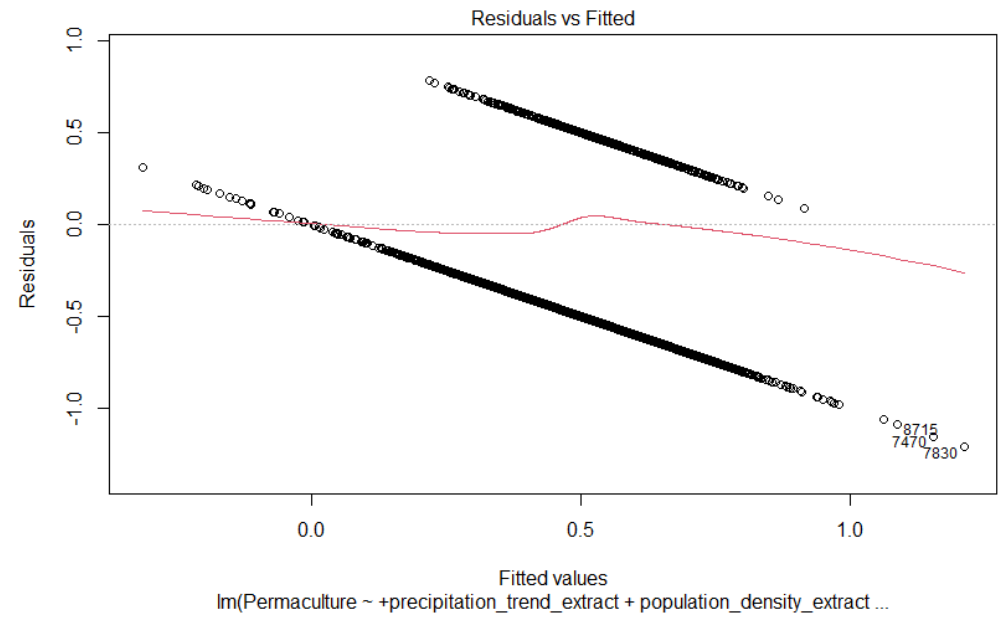

Figure A1. Residuals vs fitted for GLM model of where BGP is adopted in cases where communities are aware of BGP.

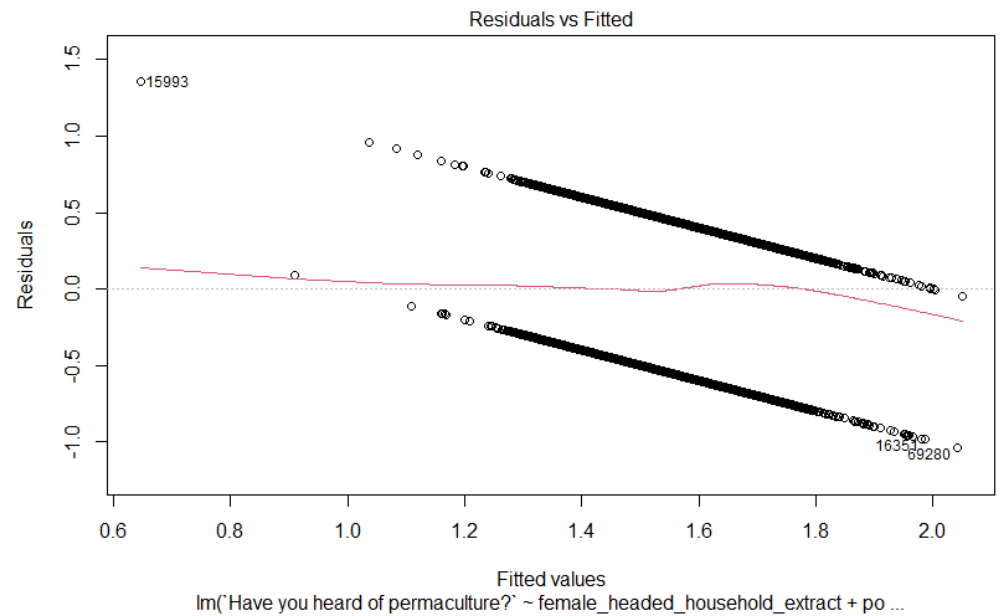

Figure A2. Residuals vs fitted plot for GLM model of communities have been aware of BG. 


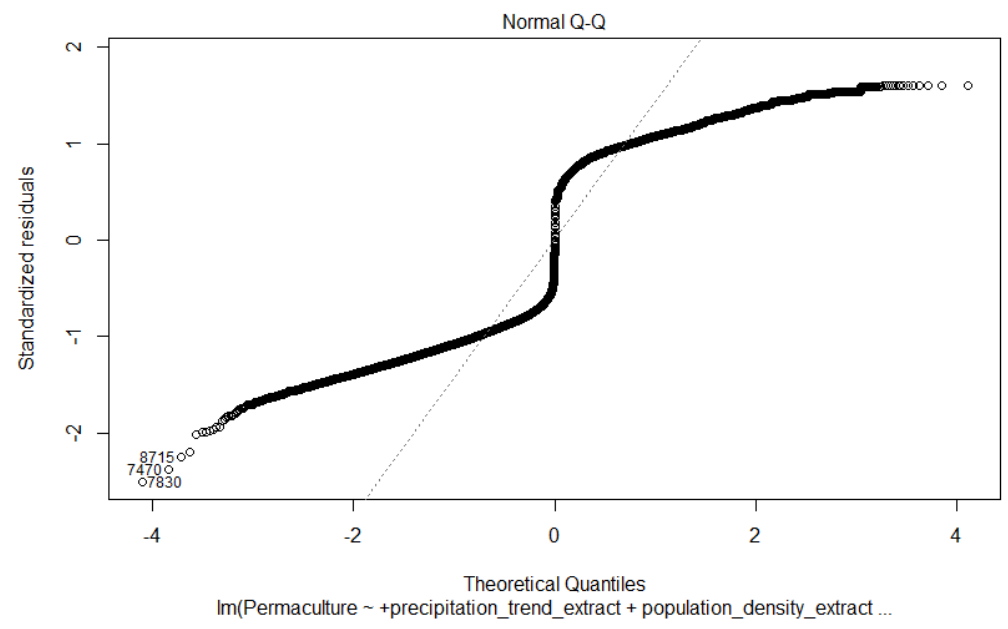

Figure A3. Q-Q plot for GLM model of communities have been aware of BG.

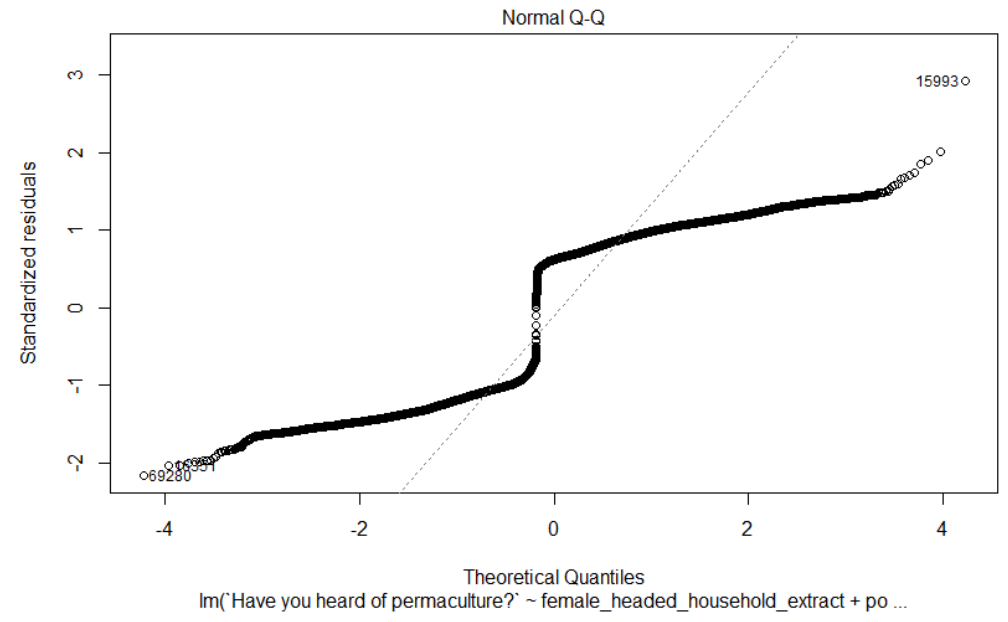

Figure A4. Q-Q plot for GLM model of where BGP is adopted in cases where communities are aware of BGP.

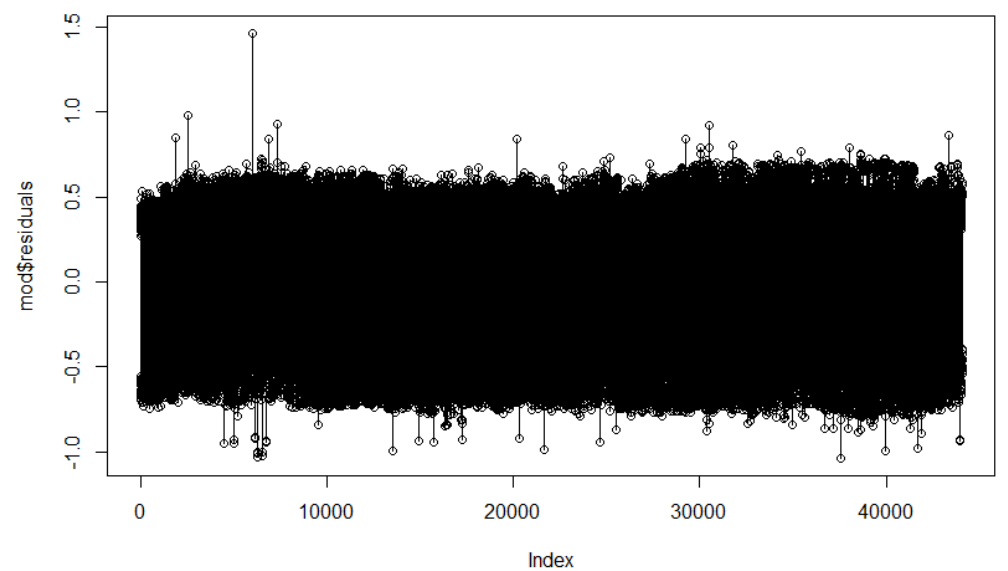

Figure A5. Residuals plot for GLM model of communities have been aware of BGP. 


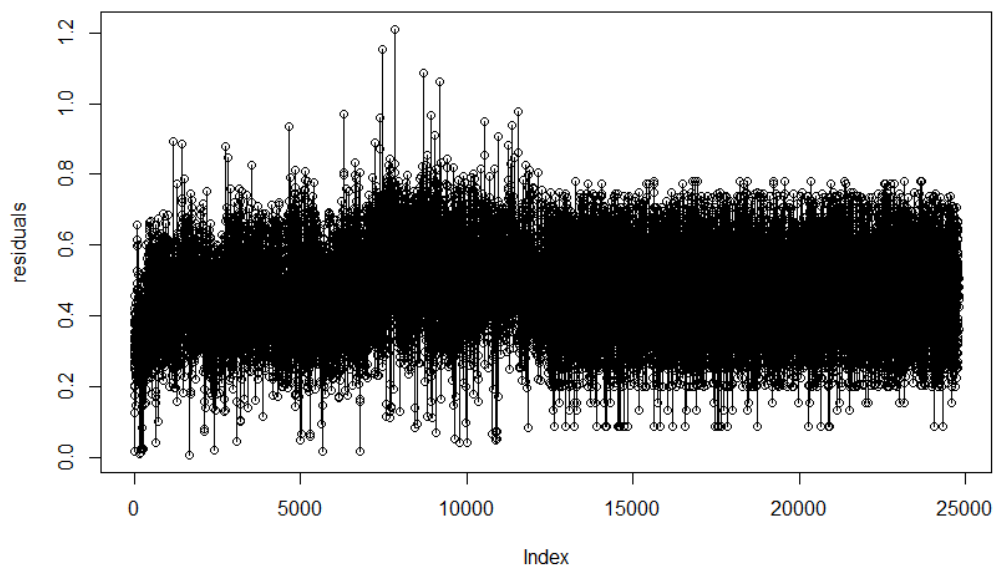

Figure A6. Residuals plot for GLM model of where BGP is adopted in cases where communities are aware of BGP.

Table A1. Variance inflation factor (VIF) for variables incorporated the GLM of where BGP has been heard of.

\begin{tabular}{cc}
\hline Variable & VIF Value \\
\hline Number of women on the Waterpoint Committee & 1.03 \\
Preventative maintenance performed on the waterpoint & 1.07 \\
How many people usually use this waterpoint & 1.09 \\
Female-headed household & 2.31 \\
Soil organic carbon & 1.29 \\
Malaria susceptibility & 2.13 \\
Poverty & 2.22 \\
Mother education & 1.21 \\
Precipitation trend & 1.43 \\
Tariff or user fee for water use & 1.39 \\
Irrigation & 1.07 \\
Riverine flooding & 1.07 \\
Market accessibility time & 1.02 \\
Maximum distance a user walks to this waterpoint & 1.21 \\
\end{tabular}

Table A2. Variance inflation factor (VIF) for variables incorporated the GLM of where BGP is practised where communities are aware of it.

\begin{tabular}{cc}
\hline Variable & VIF Value \\
\hline How many women are on the Waterpoint Committee & 1.02 \\
Preventative maintenance performed on the waterpoint & 1.05 \\
Precipitation trend & 1.16 \\
Maximum distance a user walks to this waterpoint & 1.04 \\
Market accessibility time & 1.18 \\
How many months water is not available & 1.04 \\
Population density & 1.05 \\
Riverine flooding & 1.01 \\
Healthcare infrastructure & 1.39 \\
Soil organic carbon & 1.61 \\
Mother education level & 1.44 \\
Female-headed household index & 1.58 \\
Temperature trend & 1.52 \\
\hline
\end{tabular}


Table A3. Summary of quantitative variables, description, values and their sources.

\begin{tabular}{|c|c|c|c|}
\hline Variable & Description & Source & $\begin{array}{c}\text { Minimum; Maximum; } \\
\text { Mean }\end{array}$ \\
\hline Female-headed household & $\begin{array}{l}\text { Index of number female-headed } \\
\text { households. }\end{array}$ & Source: RCMRD & $0.00 ; 100 ; 63.7$ \\
\hline Poverty index & Index of poverty level. & Source: RCMRD & $0.00 ; 99.5 ; 82.8$ \\
\hline Healthcare infrastructure & Index of healthcare infrastructure. & Source: RCMRD & $0.00 ; 100 ; 80.6$ \\
\hline Mother education level & Index of education level of mothers. & Source: RCMRD & $0.00 ; 100 ; 65.2$ \\
\hline Precipitation trend & $\begin{array}{l}\text { Long-term trend indicating increasing or } \\
\text { decreasing precipitation over the rainy } \\
\text { reason. Higher number refers to increasing } \\
\text { precipitation over the rainy season and } \\
\text { therefore more reliable rainfall. }\end{array}$ & Source: RCMRD & $0.00 ; 95.6 ; 38.1$ \\
\hline Market accessibility time & $\begin{array}{l}\text { Index of time taken to travel to closest } \\
\text { market. Higher number relates to areas } \\
\text { further from a market }\end{array}$ & Source: RCMRD & $0.14 ; 100 ; 24.3$ \\
\hline Malaria susceptibility index & $\begin{array}{l}\text { Index of malaria susceptibility using the } \\
\text { standardised } P \text {. falciparum parasite rate }\end{array}$ & Source: RCMRD & $0.00 ; 99.3 ; 56.9$ \\
\hline Literacy levels & Index of literacy levels. & Source: RCMRD & $0.00 ; 100 ; 24.1$ \\
\hline Soil organic carbon & $\begin{array}{l}\text { Higher soil organic carbon is also } \\
\text { associated with higher soil fertility and } \\
\text { moisture retention. }\end{array}$ & Source: RCMRD & $0.00 ; 57.9 ; 8.84$ \\
\hline Population density & Population density index. & Source: RCMRD & $0.00 ; 100 ; 1.32$ \\
\hline Temperature trend & $\begin{array}{l}\text { High trend in temperature indicates an } \\
\text { increase in temperature. }\end{array}$ & Source: RCMRD & $0.00 ; 100 ; 59.8$ \\
\hline Riverine flood index & $\begin{array}{l}\text { Index of the risk of an area to river } \\
\text { flooding. }\end{array}$ & Source: RCMRD & $0.00 ; 100 ; 0.48$ \\
\hline Forest fires & Index of the risk of an area to forest fires. & Source: RCMRD & $0.00 ; 63.6 ; 0.77$ \\
\hline Irrigation & $\begin{array}{c}\text { Access to irrigation. Amount of area } \\
\text { equipped for irrigation as a percentage of } \\
\text { the total area. }\end{array}$ & Source: RCMRD & $0.00 ; 100 ; 97.7$ \\
\hline $\begin{array}{l}\text { Maximum distance a user } \\
\text { walks to the WP }\end{array}$ & Distance walked one way in metres. & $\begin{array}{l}\text { Source: Waterpoint } \\
\text { survey }\end{array}$ & $0.00 ; 10000 ; 401$ \\
\hline Months water is unavailable & $\begin{array}{c}\text { Number of months in a year that water is } \\
\text { unavailable from the waterpoint }\end{array}$ & $\begin{array}{l}\text { Source: Waterpoint } \\
\text { survey }\end{array}$ & $0.00 ; 12.0 ; 0.64$ \\
\hline Number of people on WPC & $\begin{array}{l}\text { How many people on the waterpoint } \\
\text { committee }\end{array}$ & $\begin{array}{l}\text { Source: Waterpoint } \\
\text { survey }\end{array}$ & $1.00 ; 20.0 ; 9.10$ \\
\hline $\begin{array}{l}\text { Number of women on the } \\
\text { WPC }\end{array}$ & $\begin{array}{l}\text { How many people on the waterpoint } \\
\text { committee }\end{array}$ & $\begin{array}{l}\text { Source: Waterpoint } \\
\text { survey }\end{array}$ & $1.00 ; 20.0 ; 5.29$ \\
\hline $\begin{array}{l}\text { How many people usually use } \\
\text { the waterpoint }\end{array}$ & Number of regular users of the waterpoint & $\begin{array}{l}\text { Source: Waterpoint } \\
\text { survey }\end{array}$ & $1.05 ; 250 ; 115$ \\
\hline
\end{tabular}

Table A4. Summary of binary response variables.

\begin{tabular}{ccc}
\hline Variable & Number of "Yes" Responses & Number of "No" Responses \\
\hline $\begin{array}{c}\text { Is preventative maintenance } \\
\text { performed on the waterpoint? } \\
\text { Source: Waterpoint survey }\end{array}$ & 48,100 & 16,100 \\
\hline $\begin{array}{l}\text { Is there a tariff or user fee for } \\
\text { the waterpoint? Source: } \\
\text { Waterpoint survey }\end{array}$ & 51,400 & 13,900 \\
\hline
\end{tabular}


GLM with all variables for where BGP had been heard of.

Table A5. Results of generalised linear regression model for variables influencing where BGP has been heard of in Malawi combining all analysed variables. BIC Value: 13,960.35. AIC Value: $13,786.31$. The model correctly predicted $59.83 \%$ of cases where BGP had been heard of $(18,565$ correct predictions and 12,462 incorrect predictions). Significant $p$ values are marked with one or more asterisk $\left.{ }^{*}\right)$. Significance codes: ${ }^{* * *}(0<p \leq 0.001) ;{ }^{* *}(0.001<p \leq 0.01) ;{ }^{*}(0.01<p \leq 0.05)$.

\begin{tabular}{ccc}
\hline Variable & Variable Estimate $(\times \mathbf{0 . 0 0 1})$ & Significance \\
\hline Female-Headed Household & $+16.2 \pm 1.02$ & $* * *$ \\
Poverty & $+10.6 \pm 1.48$ & $* * *$ \\
Healthcare infrastructure & $-0.928 \pm 1.03$ & $\mathrm{NS}$ \\
Mother education level & $+3.84 \pm 0.393$ & $* * *$ \\
Precipitation trend & $+6.71 \pm 0.891$ & $* * *$ \\
Market accessibility time & $+2.27 \pm 0.591$ & $* * *$ \\
Malaria susceptibility & $-11.3 \pm 0.793$ & $\mathrm{NS}$ \\
Literacy level & $+1.76 \pm 1.57$ & $* * *$ \\
Soil organic carbon & $-29.2 \pm 3.11$ & $* *$ \\
Population density & $-13.5 \pm 4.91$ & $\mathrm{NS}$ \\
Temperature trend & $+0.0418 \pm 1.57$ & $* * *$ \\
Riverine flood & $-12.8 \pm 2.90$ & $* *$ \\
Maximum distance a user walks to the WP & $+0.0601 \pm 0.0228$ & $*$ \\
Distance to a BGP practising WP & $-158.8 \pm 12.46$ & $* * *$ \\
Forest fires & $+7.16 \pm 2.78$ & $\mathrm{NS}$ \\
Irrigation & $+8.62 \pm 1.74$ & $\mathrm{NS}$ \\
Number of months water not available & $+1.55 \pm 7.42$ & $\mathrm{NS}$ \\
How many people are on the WPC & $-9.45 \pm 6.93$ & $* * *$ \\
How many women are on the WPC & $-8.15 \pm 8.07$ & $* * *$ \\
How many people usually use this WP & $0.121 \pm 0.0217$ & $* * *$ \\
Preventative maintenance performed & $120 \pm 25.7$ & $-149 \pm 30.6$ \\
Tariff or user fee for water use & &
\end{tabular}

GLM with all variables for where BGP has been adopted.

Table A6. Results of generalised linear regression model for variables influencing where BGP is practised in places aware of BGP. BIC Value: 33000 . AIC Value: 32800 . Correctly predicted the status of which boreholes adopted BGP in 53.6\% of cases (3006 correct predictions and 2599 incorrect predictions). Sensitivity 0.647 , specificity 0.530 . Significant $\mathrm{p}$ values are marked with one or more asterisk $\left.{ }^{*}\right)$. Significance codes: ${ }^{* * *}(0<p \leq 0.001) ;{ }^{* *}(0.001<p \leq 0.01) ;{ }^{*}(0.01<p \leq 0.05)$.

\begin{tabular}{ccc}
\hline Variable & Variable Estimate $(\times \mathbf{0 . 0 0 1})$ & Significance \\
\hline Female-Headed Household & $-8.60 \pm 1.29$ & $* * *$ \\
Poverty & $+8.43 \pm 2.29$ & $* * *$ \\
Healthcare infrastructure & $+2.61 \pm 1.35$ & $\mathrm{NS}$ \\
Mother education level & $+4.25 \pm 0.508$ & $* * *$ \\
Precipitation trend & $+19.7 \pm 1.29$ & $* * *$ \\
Market accessibility time & $+3.32 \pm 0.777$ & $*$ \\
Malaria susceptibility & $2.458 \pm 1.11$ & $\mathrm{NS}$ \\
Literacy level & $-3.78 \pm 2.29$ & $* *$ \\
Soil organic carbon & $+46.9 \pm 4.06$ & $* *$ \\
Population density & $-27.0 \pm 9.54$ & $* * *$ \\
Temperature trend & $9.04 \pm 2.09$ & $* * *$ \\
Riverine flood & $-74.5 \pm 13.0$ &
\end{tabular}


Table A6. Cont.

\begin{tabular}{ccc}
\hline Variable & Variable Estimate $(\times \mathbf{0 . 0 0 1})$ & Significance \\
\hline Maximum distance a user walks to the WP & $+0.355 \pm 0.0284$ & $* * *$ \\
Distance to a BGP practising WP & $+9.22 \pm 15.7$ & NS \\
Forest fires & $-2.01 \pm 3.53$ & NS \\
Irrigation & $+11.4 \pm 2.54$ & $* * *$ \\
Number of months water not available & $-125 \pm 11.1$ & NS \\
Number of people on the WPC & $+12.6 \pm 9.24$ & $* * *$ \\
Number of women on the WPC & $+99.2 \pm 1.00$ & $* * *$ \\
Number of people usually use this WP & $-0.125 \pm 0.0257$ & $* *$ \\
Preventative maintenance performed & $-95.7 \pm 33.6$ & NS \\
Tariff or user fee for water use & $-44.9 \pm 41.5$ & \\
\hline
\end{tabular}

Table A7. Reasons given for rejection of BGP by communities who became aware of BGP but were not practising the technique.

\begin{tabular}{|c|c|}
\hline Reason for BGP Rejection & Incidence \\
\hline No common land at end of soakway & 13,000 \\
\hline Not interested & 7070 \\
\hline Lack of knowledge/awareness/no community training & 4310 \\
\hline Limited water/nonfunctional waterpoint & 2380 \\
\hline Limited money & 981 \\
\hline No access to seeds & 712 \\
\hline Yet to start/temporary pause & 649 \\
\hline Animals & 497 \\
\hline Salty water/poor water quality & 457 \\
\hline River nearby/natural irrigation & 64.0 \\
\hline Not allowed by health ministry/WUA/bylaws & 44.0 \\
\hline New borehole/under construction & 38.0 \\
\hline Unsuitable conditions & 37.0 \\
\hline Not allowed by landowner & 35.0 \\
\hline Conflict/disagreement & 32.0 \\
\hline Close to dambo/use special dambo & 27.0 \\
\hline No soakway/drainage at borehole & 27.0 \\
\hline Vandalism/abuse of garden & 26.0 \\
\hline Theft & 25.0 \\
\hline Work overload & 25.0 \\
\hline Borehole located in a school & 19.0 \\
\hline People use their own gardens & 16.0 \\
\hline Committee is changing/new/disorganised/not present & 13.0 \\
\hline No security & 13.0 \\
\hline Bills/charges & 10.0 \\
\hline
\end{tabular}




\section{References}

1. National Planning Commission, Malawi. Malawi 2063: Malawi's Vision An Inclusively Wealthy and Self-Reliant Nation; National Planning Commission (NPC): Lilongwe, Malawi, 2020.

2. International Monetary Fund (IMF). Malawi, Economic Development Document; IMF Country Report No. 17/184; IMF: Washington, DC, USA, 2017.

3. Food and Agricultural Organization (FAO). Africa Food and Agriculture: FAO Statistical Yearbook 2014; FAO and United Nations Regional Office for Africa: Accra, Ghana, 2014.

4. Muyanga, M.; Nyirenda, Z.; Lifeyo, Y.; Burke, W.J. The Future of Smallholder Farming in Malawi; MwAPATA Institute Working Paper No. 20/03; MwAPATA Institute: Lilongwe, Malawi, 2020.

5. Hall, C.; Macdiarmid, J.I.; Smith, P.; Dawson, T.P. The impact of climate and societal change on food and nutrition security: A case study of Malawi. Food Energy Secur. 2021, 10, e290. [CrossRef]

6. Almazroui, M.; Saeed, F.; Saeed, S.; Islam, S.; Ismail, M.; Klutse, N.A.B.; Siddiqui, M.H. Projected Change in Temperature and Precipitation Over Africa from CMIP6. Earth Syst. Environ. 2020, 4, 455-475. [CrossRef]

7. United Nations, Department of Economic and Social Affairs, Population Division. World Population Prospects: The 2015 Revision, Key Findings and Advance Tables; Working Paper No. ESA/P/WP.241; United Nations: New York, NY, USA, 2015.

8. Gomo, F.; Macleod, C.A.J.; Rowan, J.; Yeluripati, J.; Topp, K. Supporting better decisions across the nexus of water, energy and food through earth observation data: Case of the Zambezi basin. Proc. Int. Assoc. Hydrol. Sci. 2018, 376, 15-23. [CrossRef]

9. Beattie, S.; Sallu, S.M. How Does Nutrition Feature in Climate-Smart Agricultural Policy in Southern Africa? A Systematic Policy Review. Sustainability 2021, 13, 2785. [CrossRef]

10. Fisher, M.; Holden, S.T.; Thierfelder, C.; Katengeza, S.P. Awareness and adoption of conservation agriculture in Malawi: What difference can farmer-to-farmer extension make? Int. J. Agric. Sustain. 2018, 16, 310-325. [CrossRef]

11. Bouwman, T.I.; Andersson, J.A.; Giller, K.E. Adapting yet not adopting? Conservation agriculture in Central Malawi Agriculture. Ecosyst. Environ. 2020, 307, 107224. [CrossRef]

12. Pavelic, P.; Giordano, M.; Keraita, B.; Ramesh, V.; Rao, T. Groundwater Availability and Use in Sub-Saharan Africa: A Review of 15 Countries; Water Management Institute (IWMI): Colombo, Sri Lanka, 2012.

13. Kalin, R.M.; Mwanamveka, J.; Coulson, A.B.; Robertson, D.J.C.; Clark, H.; Rathjen, J.; Rivett, M.O. Stranded Assets as a Key Concept to Guide Investment Strategies for Sustainable Development Goal 6. Water 2019, 11, 702. [CrossRef]

14. Truslove, J.P.; Miller, A.V.M.; Mannix, N.; Nhlema, M.; Rivett, M.O.; Coulson, A.B.; Mleta, P.; Kalin, R.M. Understanding the Functionality and Burden on Decentralised Rural Water Supply: Influence of Millennium Development Goal 7c Coverage Targets. Water 2019, 11, 494. [CrossRef]

15. Mannix, N.; Norrie, J.; Paterson, F.; Nhlema M.; Mleta, P.; Nkhata, M.; Wanangwa, G.; Kumwenda, S.; Clarke, D.; Kalin, R.M. Making the case for improved planning, construction and testing of water supply infrastructure in Malawi. In Proceedings of the 41st WEDC International Conference, Egerton University, Nakuru, Kenya, 9-13 July 2018.

16. UN-Water. Summary Progress Update 2021: SDG 6-Water and Sanitation for All. 2021. Available online: https:/ /www.unwater. org/publications / summary-progress-update-2021-sdg-6-water-and-sanitation-for-all/ (accessed on 3 September 2021).

17. United Nations. Interim Report of the Special Rapporteur on the Right to Food; Seventy-Fourth Session. 2019. Available online: https:/ / undocs.org/A/74/164 (accessed on 3 September 2021).

18. Skinner, B. G003: Apron Slabs for Water Points: An Engineer's Guide; WEDC, Loughborough University: Loughborough, UK, 2012.

19. Howard, G.; Blogh, C.; Goldstein, G.; Morgan, J.; Pruss-Ustun, A. Healthy Villages: A Guide for Communities and Community Health Workers; World Health Organization: Geneva, Switzerland, 2002.

20. Rivett, M.; Halcrow, A.; Schmalfuss, J.; Stark, J.; Truslove, J.; Kumwenda, S.; Harawa, K.; Nhlema, M.; Songola, C.; Wanangwa, G.; et al. Local scale water-food nexus: Use of borehole-garden permaculture to realise the full potential of rural water supplies in Malawi. J. Environ. Manag. 2018, 209, 354-370. [CrossRef]

21. Lovell, C.J.; Batchelor, C.H.; Waughray, D.K.; Semple, A.J.; Mazhangara, E.; Mtetwa, G.; Murata, M.; Brown, M.W.; Dube, T.; Thompson, D.M.; et al. Small Scale Irrigation Using Collector Wells Pilot Project-Zimbabwe; Final report October 1992-January 1996; Institute of Hydrology: Wallingford, UK, 1996; 106p.

22. Conrad, A. We Are Farmers: Agriculture, Food Security, and Adaptive Capacity among Permaculture and Conventional Farmers in Central Malawi. Ph.D. Dissertation, American University, Washington DC, USA, 2014.

23. Nordin, K.; Nordin, S. Never Ending Food in Malawi. In Alliance for Food Sovereignty in Africa (AFSA)—Agroecology Case Study; 2014. Available online: https://afsafrica.org/wp-content/uploads/2015/11/Never-Ending-Food-in-Malawi.pdf (accessed on 3 September 2021).

24. Okech, B.A.; Mwobobia, I.K.; Kamau, A.; Muiruri, S.; Mutiso, N.; Nyambura, J.; Mwatele, C.; Amano, T.; Mwandawiro, C.S. Use of Integrated Malaria Management Reduces Malaria in Kenya. PLoS ONE 2008, 3, e4050. [CrossRef] [PubMed]

25. Chatham House Webinar: Malawi's Priorities for Inclusive Prosperity. Available online: https://www.youtube.com/watch?v= 2YF7Pzh7TgM.Minute38:50 (accessed on 22 September 2021).

26. Chaudhuri, S.; Roy, M.; McDonald, L.M.; Emendack, Y. Reflections on farmers' social networks: A means for sustainable agricultural development? Environ. Dev. Sustain. 2021, 23, 2973-3008. [CrossRef]

27. Munasib, A.; Jordan, J. The Effect of Social Capital on the Choice to Use Sustainable Agricultural Practices. J. Agric. Appl. Econ. 2011, 43, 213-227. [CrossRef] 
28. Läpple, D.; Holloway, H.; Lacombe, D.J.; O’Donoghue, C. Sustainable technology adoption: A spatial analysis of the Irish Dairy Sector. Eur. Rev. Agric. Econ. 2017, 44, 810-835. [CrossRef]

29. Tessema, L.; Asafu-Adjaye, J.; Menale, K.; Thilak, M. Do neighbours matter in technology adoption? The case of conservation tillage in northwest Ethiopia. Afr. J. Agric. Resour. Econ. 2016, 11, 211-225.

30. The World Bank Data. Available online: data.worldbank.org/indicator/NV.AGR.TOTL.ZS?locations=MW (accessed on 8 October 2021).

31. World Trade Organisation. Trade Profiles: Malawi. 2020. Available online: https://www.wto.org/english/res_e/publications_e/ trade_profiles20_e.htm (accessed on 3 September 2021).

32. World Bank. Malawi Drought Recovery \& Resilience Project Report. Available online: https://www.worldbank.org/en/news/ loans-credits/2016/11/08/malawi-drought-recovery-and-resilience-project (accessed on 3 September 2021).

33. Pauw, K.; Thurlow, J.; Seventer, D. Droughts and Floods in Malawi; IFPRI Discussion Paper; International Food Policy Research Institute (IFPRI): Washington, DC, USA, 2010.

34. Kelly, L.; Bertram, D.; Kalin, R.; Ngongondo, C. Characterization of groundwater discharge to rivers in the Shire River Basin, Malawi. Am. J. Water Sci. Eng. 2019, 5, 127-138. [CrossRef]

35. Calder, I.R.; Hall, R.L.; Bastable, H.G.; Gunston, H.M.; Osborne S.; Chirwa, A.; Kafundu, R. The impact of land use change on water resources in sub-Saharan Africa: A modelling study of Lake Malawi. J. Hydrol. 1995, 170, 123-135. [CrossRef]

36. Minde, I.J.; Kowero, G.; Nhuhi, D.; Luhanga, J. Agricultural land expansion and deforestation in Malawi. For. Trees Livelihoods 2001, 11, 167-182. [CrossRef]

37. Pullanikkatil, D.; Palamuleni, L.g.; Tabukeli R.M. Land use/land cover change and implications for ecosystems services in the Likangala River Catchment, Malawi. Phys. Chem. Earth 2016, 93, 96-103. [CrossRef]

38. Truslove, J.P.; Coulson, A.B.; Nhlema, M.; Mbalame, E.; Kalin, R.M. Reflecting SDG 6.1 in Rural Water Supply Tariffs: Considering 'Affordability' Versus 'Operations and Maintenance Costs' in Malawi. Sustainability 2020, 12, 744. [CrossRef]

39. Miller, A.V.; Nhlema, M.; Kumwenda, S.; Mbalame E.; Uka, Z.; Feighery, J.; Kalin, R. Evolving water point mapping to strategic decision making in rural Malawi. In Proceedings of the 41st WEDC International Conference, Egerton University, Nakuru, Kenya, 9-13 July 2018.

40. mWater. Available online: https://www.mwater.co/ (accessed on 3 September 2021).

41. Onwuegbuzie, A.; Combs, J. Emergent data analysis techniques in mixed methods research: A synthesis. SAGE Handb. Mix. Methods Soc. Behav. Res. 2010, 2, 398.

42. Jara-Rojas, R.; Bravo-Ureta, B.E.; Díaz, J. Adoption of water conservation practices: A socioeconomic analysis of small-scale farmers in Central Chile. Agric. Syst. 2012, 110, 54-62. [CrossRef]

43. Lee, D.R. Agricultural Sustainability and Technology Adoption: Issues and Policies for Developing Countries. Am. J. Agric. Econ. 2005, 87, 1325-1334. [CrossRef]

44. Ajayi, O.C. User Acceptability of Sustainable Soil Fertility Technologies: Lessons from Farmers' Knowledge, Attitude and Practice in Southern Africa. J. Sustain. Agric. 2007, 30, 21-40. [CrossRef]

45. Tey, Y.S.; Li, E.; Bruwer, J.; Abdullah, A.M.; Brindal, M.; Radam, A.; Ismail, M.M.; Darham, S. Variables influencing the adoption of sustainable agricultural practices in developing countries. Environ. Eng. Manag. J. 2013, 16, 337-349. [CrossRef]

46. Regional Centre for Mapping of Resources for Development (RCDMRD) Geoportal. Available online: http:/ / geoportal.rcmrd.org/ (accessed on 3 September 2021).

47. SERVIR-Eastern and Southern Africa. Available online: https://servirglobal.net/ (accessed on 3 September 2021).

48. Humanitarian Data Exchange (HDX). Available online: \$data.humdata.org/dataset/2018_malawi_ta_dataset-updated-admin3\$ (accessed on 6 September 2021).

49. Raster: Geographic Data Analysis and Modeling. Available online: https://CRAN.R-project.org/package=raster (accessed on 3 September 2021).

50. R Core Team. R: A Language and Environment for Statistical Computing; R Foundation for Statistical Computing: Vienna, Austria, 2020. Available online: https:/ / www.R-project.org/ (accessed on 24 September 2021).

51. RStudio Team. RStudio: Integrated Development for R. RStudio, PBC, Boston, MA. 2020. Available online: http:/ / www.rstudio. $\mathrm{com} /$ (accessed on 24 September 2021).

52. McCullagh, P.; Nelder, J.A. Generalized Linear Models, 2nd ed.; Routledge: Oxfordshire, UK 1989.

53. Dobson, A.J. An Introduction to Generalized Linear Models; Chapman and Hall: London, UK, 1990.

54. GLM. Available online: https://www.rdocumentation.org/packages/stats/versions/3.6.2/topics/glm (accessed on 3 September 2021).

55. Schwarz, G. Estimating the Dimension of a Model. Ann. Stat.. 1978, 6, 461-464. [CrossRef]

56. Shipe, M.E.; Deppen, S.A.; Farjah, F.; Grogan, E.L. Developing prediction models for clinical use using logistic regression: An overview. J Thorac. Dis. 2019, 11, 574-584. [CrossRef] [PubMed]

57. Pham, B.T.; Qi, C.; Ho, L.S.; Nguyen-Thoi, T.; Al-Ansari, N.; Nguyen, M.D.; Nguyen, H.D.; Ly, H.B.; Le, H.V.; Prakash, I. A Novel Hybrid Soft Computing Model Using Random Forest and Particle Swarm Optimization for Estimation of Undrained Shear Strength of Soil. Sustainability 2020, 12, 2218. [CrossRef]

58. Predict. Available online: https://www.rdocumentation.org/packages/car/versions/3.0-11/topics/Predict (accessed on 3 September 2021). 
59. García-Portugués, E. Notes for Predictive Modeling; Version 5.9.0. 2021. Available online: https://bookdown.org/egarpor/PMUC3M/ (accessed on 3 September 2021).

60. Lunardon, N.; Menardi, G.; Torelli, N. ROSE: A Package for Binary Imbalanced Learning. R J. 2014, 6, 82-92. [CrossRef]

61. Cordón, I.; García, S.; Fernández, A.; Herrera, F. Imbalance: Oversampling algorithms for imbalanced classification in R. Knowl. Based Syst. 2018, 161, 329-341. [CrossRef]

62. LM. Available online: https://www.rdocumentation.org/packages/stats/versions/3.6.2/topics/lm (accessed on 3 September 2021).

63. VIF. Available online: https://www.rdocumentation.org/packages/regclass/versions/1.6/topics/VIF (accessed on 3 September 2021).

64. James, G.; Witten, D.; Hastie, T.; Tibshirani, R. Linear Regression. An Introduction to Statistical Learning; Springer: New York, NY, USA, 2013; Volume 13, pp. 32-58.

65. Carter, R.C.; Ross, I. Beyond 'Functionality' of Handpump-Supplied Rural Water Services in Developing Countries. Waterlines 2016, 35, 94-110. [CrossRef]

66. Ngwira, A.; Johnsen, F.H.; Aune, J.B.; Mekuria, M.; Thierfelder, C. Adoption and extent of conservation agriculture practices among smallholder farmers in Malawi. J. Soil Water Conserv. 2014, 69, 107-119. [CrossRef]

67. Kassie, M.; Jaleta, M.; Shiferaw, B.; Mmbando, F.; Muricho, G. Plot and Household-Level Determinants of Sustainable Agricultural Practices in Rural Tanzania. Environ. Dev. 2012, 12, 41.

68. Muench, S.; Bavorova, M.; Pradhan, P. Climate Change Adaptation by Smallholder Tea Farmers: A Case Study of Nepal. Environ. Sci. Policy 2021, 116, 136-146. [CrossRef]

69. Chinseu, E.; Dougill, A.; Stringer, L. Why do smallholder farmers dis-adopt conservation agriculture? Insights from Malawi. Land Degrad Dev. 2019, 30, 533-543. [CrossRef]

70. Murray, U.; Gebremedhin, Z.; Brychkova, G.; Spillane, C. Smallholder Farmers and Climate Smart Agriculture: Technology and Labor-productivity Constraints amongst Women Smallholders in Malawi. Gender Technol. Dev. 2016, 20, 117-148. [CrossRef]

71. Djenontin, I.N.S.; Zulu, L.C.; Ligmann-Zielinska, A. Improving Representation of Decision Rules in LUCC-ABM: An Example with an Elicitation of Farmers' Decision Making for Landscape Restoration in Central Malawi. Sustainability 2020, $12,5380$. [CrossRef]

72. Mussa, R.; Pauw, K. Poverty in Malawi: Current Status and Knowledge Gaps; MALAWI STRATEGY SUPPORT PROGRAM (MaSSP); Policy Note 9; International Food Policy Research Institute: Washington, DC, USA, 2011.

73. Crona, B.I.; Bodin, O. WHAT you know is WHO you know? Communication patterns among resource users as a prerequisite for co-management. Ecol. Soc. 2006, 11, 1-23. [CrossRef]

74. Pratiwi, A.; Suzuki, A. Effects of farmers' social networks on knowledge acquisition: Lessons from agricultural training in Indonesia. J. Econ. Struct. 2017, 6, 1-23. [CrossRef]

75. Rivett, M.O.; Budimir, L.; Mannix, N.; Miller, A.V.M.; Addison, M.J.; Moyo, P.; Wanangwa, G.J.; Phiri, O.L.; Songola, C.E.; Nhlema, M.; et al. Responding to salinity in a rural African alluvial valley aquifer system: To boldly go beyond the world of hand-pumped groundwater supply? Sci. Total. Environ. 2019, 653, 1005-1024. [CrossRef]

76. Kellert, S.R.; Mehta, J.N.; Ebbin, S.A.; Lichtenfeld, L.L. Community Natural Resource Management: Promise, Rhetoric, and Reality. Soc. Nat. Resour. 2020, 13, 705-715.

77. Adams, T.; Gerber, J.D.; Amacker, M. Constraints and opportunities in gender relations: Sugarcane outgrower schemes in Malawi. World Dev. 2019, 122, 282-294. [CrossRef]

78. Arlosoroff, S.; Tschannerl, G.; Grey, D.; Journey, W.; Karp, A.; Langeneffer, O.; Roche, R. Community Water Supply: The Handpump Option; World Bank: Washington, DC, USA, 1987.

79. Hope, R.A. Is community water management the community's choice? Implications for water and development policy in Africa. Water Policy 2015, 17, 664-678. [CrossRef]

80. Chowns, E. Is Community Management an Efficient and Effective Model of Public Service Delivery? Lessons from the Rural Water Supply Sector in Malawi. Public Adm. Dev. 2015, 35, 263-276. [CrossRef] 